\title{
UMA METODOLOGIA DE PROGRAMAS DE PESQUISA CIENTIIFICA, SEGUNDO LAKATOS
}

Alziro César M. Rodrigues*

SÍNTESE - Um dos aspectos mais amplamente abordados em estudos recentes de Filosofia da Ciência tem sido o debate epistemológico criado em torno das idéias de Thomas Kuhn e Karl Popper. Na tentativa de resolver a controvérsia estabelecida, Imre Lakatos propôs a falsificação metodológica sofisticada. $O$ presente artigo coloca em foco esta proposição, discutindo sua formulação e destacando a contribuição de Lakatos ao raciocínio epistemológico.

PALAVRAS-CHAVE - filosofia da ciência, Lakatos, falsificação metodológica.
ABSTRACT - One of the most discussed subjects in the field of Philosophy of Science is the epistemological discussion on the ideas of Thomas Kuhn and Karl Popper. In order to offer a solution to that controversy, Imre Lakatos proposed the sophisticated methodological falsification (SMF). This article examines this proposition, discusses its formulation and details the contribution of Lakatos to the epistemological thinking.

KEY WORDS - philosophy of science, Lakatos, methodological falsification.

\section{Introdução}

Kuhn (1970) propôs um modelo de progresso científico fundamentado na noção de paradigma. Segundo Kuhn, a ciência avança num ciclo que se inicia a partir de um paradigma aceito por toda uma comunidade científica e que é estudado amplamente durante um período de "ciência normal". Em função de anomalias que se acumulam, um período de crise pode resultar desse processo, seguindo-se a queda do velho paradigma e o surgimento de uma outra "revelação científica".

Popper (1972) questionou a representação "kuhniana" do progresso científico como uma sucessão de paradigmas audaciosos e suas dramátiças mudanças. Popper afirmou que o progresso científico pode ser visto como uma proliferação de teonias rivais, ou seja, de revolução permanente. Para Popper, a ciência é a revolução permanente e a crítica é o âmago do trabalho científico.

* Professor da Faculdade de Ciências Políticas e Econômicas da PUCRS. Doutor em Administração pela École des Hautes Études Commerciales (HEC), França.

\begin{tabular}{|l|l|l|l|l|l|} 
VERITAS & Porto Alegre & v. 43 & $\mathrm{n}^{\mathbf{0}} 1$ & Março 1998 & p. 161-168 \\
\hline
\end{tabular}


Para Kuhn, ao contránio, a revolução é excepcional e, certamente, extracientífica, sendo a crítica, durante os tempos "normais", um anátema. Segundo Kuhn, a idéia de que alguém, fundamentado na refutação, pode peđir a rejeição ou mesmo a eliminação de uma teoria dominante constitui uma falsificação simples. A crítica da teoria dominante e das proposições de novas teorias são possíveis em raros momentos de crise.

Para resolver esta controvérsia, Lakatos introduziu a noção de um programa de pesquisa. No lugar de múltiplas definições associadas ao termo paradigma, a noção "lakatosiana" não é ambígua em relação às características que a constituem. A perspectiva "lakatosiana" da falsificação metodológica sofisticada exorta a existência e a vantagem de múltiplos fundamentos teóricos numa disciplina. Em cada programa de pesquisa, esta perspectiva "lakatosiana" retém a noção "kuhniana" de resolver problemas específicos com teorias associadas.

Além disso, a perspectiva "lakatosiana" combina tanto princípios tradicionais do empirismo (como a falsificação) quanto noções relativistas contemporâneas (como o contexto da pesquisa na forma de programas de pesquisa).

\section{A falsificação de teorias}

A justificação, ou seja, a identificação do conhecimento com o conhecimento comprovado, foi a tradição dominante do pensamento racional durante várias décadas. Popper afirmou que todas as teorias não são comprováveis. Popper (1972b) foi o primeiro filósofo a desenvolver a falsificação como um método alternativo de justificativa de teoria com o objetivo de superar várias dificuldades associadas ao empirismo lógico. Os falsificacionistas argúem que a prática científica não pode ser racionalmente defendida se ela avança indutivamente, e que todas as teorias científicas são, portanto, não-comprováveis.

Três principais versões de falsificação são discutidas: a falsificação dogmática, a falsificação metodológica simples e a falsificação metodológica sofisticada. Cada uma destas versões de falsificação são apresentadas a seguir.

\section{A falsificação dogmática}

Neste tipo de falsificação, uma vez que a teoria existente seja desaprovada pela descoberta de um simples exemplo que a refuta, ela deve ser eliminada do corpo de teorias científicas. Enquanto que todas as teorias são consideradas falíveis (ou falsificáveis), os falsificacionistas dogmáticos assumem a existência de uma base empírica infalível. Entretanto, é impossivel refutar uma teoria de uma forma conclusiva porque as situações reais de teste dependem de várias coisas além da teoria sob investigação. O ponto central da falsificação dogmática é o reconhecimento de que todas as teorias são igualmente conjeturais.

Segundo Lakatos, a falsificação dogmática repousa, entretanto, sobre duas hipóteses falsas e sobre um estreito critério de demarcação entre científico e nãocientífico. A primeira hipótese é que existe, por um lado, um fronteira natural e psicológica entre as proposições teóricas ou especulativas e, por outro lado, pro- 
posições fatuais ou observáveis. A segunda hipótese é que se uma proposição satisfaz o critério de ser fatual ou observável, então ela é verdadeira.

Essas hipóteses são completadas por um critério de demarcação: somente as teorias que são "científicas", que interditam certos estados observáveis de coisas são, de fato, não-comprováveis. Ora, uma teoria é científica se ela tem uma base empírica. Para Lakatos, as duas hipóteses são, portanto, falsas. A psicologia atesta contra a primeira; a lógica contra a segunda e, finalmente, o julgamento metodológico atesta contra o critério de demarcação. Não há nenhuma demarcação entre as proposições observáveis e teóricas. Mesmo se houvesse tal demarcação, a lógica destruiria a segunda hipótese porque nenhuma proposição fatual pode ser provada a partir de uma experiência. Proposições podem ser derivadas somente de outras proposições. Elas não podem derivar de fatos.

Se proposições fatuais não podem ser comprovadas, então elas são falíveis. Se elas são faliveis, então o choque entre teorias e proposições fatuais não representa falsificações mas, simplesmente, inconsistências. Portanto, não se poderia comprovar teorias e também não se poderia não comprová-las. Esta demarcação entre as teorias não-comprovadas e a base empirica comprovada não existe: todas as proposições de ciência são teóricas e, portanto, falíveis.

Se aceitarmos o critério de demarcação da falsificação dogmática e também a idéia de que os fatos podem comprovar proposições fatuais, deve-se assumir que as mais importantes (senão todas) teorias propostas na história da ciência são metafísicas. Se aceitarmos ainda tal critério de demarcação, nega-se, então, que os fatos podem comprovar proposições. Estariamos, portanto, certamente num estado de ceticismo completo. Então toda ciência revela-se metafísica irracional e deveria ser rejeitada. As teorias científicas não são somente não-comprováveis, mas elas são igualmente não-refutáveis.

\section{A falsificação metodológica simples}

A perspectiva de falsificação metodológica simples de Popper (1972) tenta salvar a ciência do ceticismo através da demonstração de que a ciência não é somente um corpo de asserções mas também um sistema de convenções. Estas convenções são institucionalizadas e reforçadas pela comunidade científica. É reconhecido que os processos de testes empíricos não podem ser fatos sem uma série de decisões metodológicas.

A falsificação metodológica difere bastante da falsificação dogmática. A falsificação metodológica separa o rejeito da refutação. Se uma teoria é falsificada, ela é, portanto, comprovadamente falsa. Se ela é falsificada, ela pode, contudo, ainda ser verdadeira. Se nós seguimos um tipo de falsificação fundamentada na eliminação de uma teoria, nós podemos chegar a eliminar a verdadeira teoria e aceitar a falsa. A falsificação metodológica propõe, de fato, um novo critério de demarcação: somente aquelas teorias que interditam certos estados observáveis das coisas, e, portanto, podem ser falsificadas e rejeitadas, são científicas. Ou seja, uma teoria é científica (ou aceitável) se ela tem uma base empírica.

O critério de demarcação metodológica parece ser mais liberal que o critério dogmático. O primeiro permite que várias teorias possam ser qualificadas como 
científicas. A falsificação metodológica prevê algumas medidas de controle para reduzir os riscos de erros de uma certa observação. O controle mais simples é a repetição do experimento. Um outro controle é o reforço do potencial de falsificação através de uma hipótese falsificável bem corroborada.

Há duas caracteristicas cruciais comuns à falsificação dogmática e à falsificação metodológica que são claramente dissonantes com a história atual da ciência: a) um teste é (ou deveria ser) somente uma confrontação entre a teoria e o experimento; b) o único resultado interessante de tal confrontação é a falsificação: as descobertas são refutações de hipóteses científicas. Entretanto, a história da ciência sugere que: 1) um teste é a confrontação entre teorias rivais e a experiência; 2) certas experiências mais interessantes resultaram na confirmação ao invés da falsificação.

Mas se a história da ciência não se alinha à teoria da racionalidade científica, existem duas alternativas. Uma é a de abandonar os esforços para buscar uma explicação racional ao sucesso da ciência. A outra é a de tentar, pelo menos, reduzir o elemento convencional na falsificação e substituir a versão simples da falsificação metodológica por uma versão sofisticada que possa dar um novo fundamento de falsificação e também recuperar a metodologia e a idéia de progresso científico.

\section{A falsificação metodológica sofisticada}

A falsificação metodológica sofisticada difere da falsificação metodológica simples em relação às regras de aceitação (ou critérios de demarcação) e suas regias de falsificação ou eliminação. Para a falsificação metodológica sofisticada, as teorias que podem ser interpretadas como experimentalmente falsificáveis são "aceitáveis" ou "científicas". Uma teoria só é aceitável ou científica se ela tem um conteúdo empírico corroborado mais significativo que a precedente (ou a rival). $\mathrm{Ou}$ seja, somente se ela conduz à descoberta de fatos novos.

Por exemplo, a falsificação metodológica sofisticada considera uma teoria científica T como falsificada se, e somente se, uma outra teoria T' tenha sido proposta com as características seguintes:

a) T' tem um conteúdo empírico mais significativo em relação à T. Ou seja, T' prediz fatos novos, não-comprováveis para $\mathrm{T}$, ou mesmo esquecidos por $\mathrm{T}$;

b) T' explica o sucesso precedente de T, isto é, todo o conteúdo não refutado de T está no conteúdo de T';

c) algum conteúdo mais significativo de 'T' é corroborado.

Na estrutura da falsificação metodológica sofisticada, uma simples crítica via evidência de refutação não é jamais suficiente para a falsificação da teoria, visto que ninguém avalia uma teoria simplesmente, mas uma série de teorias num programa de pesquisa. Portanto, cada teoria científica deve ser avaliada com suas hipóteses auxiliares, condições iniciais e, especialmente, com as teorias precedentes. Então, é uma série de teorias que é avaliada ao invés de teorias isoladas.

A falsificação metodológica sofisticada muda o foco do problema de como avaliar teorias para o problema de como avaliar uma série de teorias. Somente uma série de teorias pode ser considerada como científica ou não-científica. Ao contrá- 
rio da falsificação metodológica simples, nenhum experimento, relação experimental, proposição de observação ou hipótese falsificável pode, sozinha, conduzir à falsificação. De fato, não há falsificação antes do surgimento de uma teoria melhor. Lakatos considera uma teoria como falsificada quando ela é substituída por uma teoria com um conteúdo mais corroborado.

Mas se a falsificação depende do surgimento de melhores teorias, então a falsificação não é simplesmente uma relação entre a teoria e a base empírica, mas, de fato, uma relação múltipla entre as teorias concorrentes, a base empírica original e o crescimento empírico que resulta da concorrência. Assim, o elemento crucial da falsificação é se a nova teoria oferece uma informação mais significativa comparada à teoria precedente e se uma parte dessa informação mais significativa é corroborada.

Uma série de teorias é teoricamente progressiva (ou constitui uma problemática teoricamente progressiva) se cada nova teoria traz um conteúdo empirico mais significativo que a precedente, ou seja, se ela prediz algum fato novo inesperado. Uma série de teorias teoricamente progressiva pode também ser empiricamente progressiva se uma parte deste conteúdo empírico mais significativo é também corroborado, ou seja, se cada nova teoria conduz a uma verdadeira descoberta de algum fato novo.

Pode-se avançar mais dizendo que uma problemática é progressiva se ela é, ao mesmo tempo, teoricamente e empiricamente progressiva. Do contrário, ela é degenerativa. Consideram-se problemáticas como científicas somente se elas são pelo menos teoricamente progressivas. Do contrário, são rejeitadas como pseudocientíficas. O progresso é medido pelo grau no qual uma problemática é progressiva; pelo grau no qual as séries de teorias conduzem à descoberta de fatos novos.

A idéia da proliferação de teorias é muito mais importante para a falsificação metodológica sofisticada que para a falsificação metodológica simples. Para esta última, a ciência avança através de mudanças experimentais repetidas de teorias. Novas teorias rivais podem acelerar o avanço mas elas não são necessárias. A proliferação constante de teorias é opcional e não mandatária.

De acordo com a falsificação metodológica sofisticada, a proliferação de teorias não pode esperar até a refutação da teoria aceita. Enquanto que a falsificação metodológica simples reforça a urgência da substituição de uma hipótese falsificada por uma outra hipótese melhor, a falsificação metodológica sofisticada não força o teórico a ir buscar uma teoria melhor, simplesmente porque a falsificação não pode preceder a uma teoria melhor.

A falsificação metodológica sofisticada substitui o conceito de teoria como conceito de base da lógica da descoberta pelo conceito de séries de teorias. Portanto, há uma sucessão de teorias e não uma só teoria que é avaliada como científica ou pseudo-científica. Mas os elementos de tais séries de teorias são normalmente ligados a uma notável continuidade que lhes é alocada nos programas de pesquisa. Esta continuidade desempenha um papel vital na história da ciência. Os problemas principais da lógica da descoberta só podem, portanto, ser discutidos dentro de uma estrutura de uma metodologia de programas de pesquisa. 


\section{Uma metodologia de programas de pesquisa cientifica}

Lakatos discute o problema da avaliação objetiva do crescimento científico em termos de problemáticas progressivas ou degenerativas nas séries de teorias científicas. As séries mais importantes no crescimento da ciência são caracterizadas por uma certa continuidade que conecta seus membros. Esta continuidade evolui ao longo de um programa de pesquisa genuíno.

Este programa consiste de regras metodológicas: há pessoas que dizem quais são os "caminhos" de pesquisa a evitar (heuristica negativa) e há outras que indicam quais os "caminhos" a seguir (heurística positiva). A ciência em si pode ser considerada como um amplo programa de pesquisa. $\mathrm{O}$ quadro da página a seguir destaca dez pontos centrais da abordagem de Lakatos sobre a metodologia de programas de pesquisa científica.

\section{A heuństica negativa e a heunistica positiva}

Todos os programas de pesquisa científica podem ser caracterizados pelo seu hard core e a heurística negativa nos interdita de acessar este hard core. Por outro lado, devemos utilizar nossa capacidade para articular ou mesmo inventar hipóteses auxiliares, que formam um cinturão protetor em torno desse "coração". Um programa de pesquisa é bem-sucedido se tudo conduz a uma problemática progressiva.

Um exemplo de um programa de pesquisa de sucesso é a teoria da gravidade de Newton. Neste programa, as três leis fundamentais da dinâmica e a lei da gravidade representam a heurística negativa porque elas são irrefutáveis.

Além da heurística negativa, os programas de pesquisa são caracterizados também pela heurística positiva. Num programa de pesquisa, as anomalias não são jamais completamente esgotadas. Poucos pesquisadores dão a atenção necessária às refutações. De fato, eles têm uma política de pesquisa de longo prazo que antecipa essas refutações. Essa política de pesquisa, ou ordem de pesquisa, é definida na heuristica positiva do programa de pesquisa.

A heurística negativa especifica o hard core do programa, que é irrefutável pela decisão metodológica de seus protagonistas. A heurística positiva, por seu lado, consiste de um conjunto parcialmente articulado de sugestões ou de indicações sobre como mudar ou desenvolver as variantes refutáveis do programa de pesquisa, ou seja, como modificar o cinturão protetor refutável.

A heuristica positiva define um programa que lista uma cadeia ou modelos mais complicados que simulam a realidade. A atenção do cientista está concentrada na construção de seus modelos segundo instruções que são estabelecidas na parte positiva de seu programa. Pode-se avaliar programas de pesquisa pelo seu poder heurístico: quanto de fatos novos eles produziram; qual é sua capacidade de explicar suas refutações ao longo de seu desenvolvimento. Assim, a metodologia dos programas de pesquisa científica contam pela relativa autonomia da ciência teórica: um fato histórico cuja racionalidade não pode ser explicada pelos primeiros falsificazionistas. 


\begin{tabular}{|c|c|}
\hline 1. A ciência e a realidade & $\begin{array}{l}\text { A direção da ciência é determinada principalmente } \\
\text { pela imaginação criativa do homem e não pelo } \\
\text { universo dos fatos. Assim, a reconstrução racional } \\
\text { do progresso científico chega ao mundo das idéias. }\end{array}$ \\
\hline 2. A compreensão da ciência & $\begin{array}{l}\text { O processo pelo qual os programas de pesquisa } \\
\text { são estabelecidos, justificados e aceitos } \\
\text { numa comunidade científica são necessários } \\
\text { para uma apreciação da ciência. }\end{array}$ \\
\hline 3.A ciência e o contexto & $\begin{array}{l}\text { A crítica das teorias científicas está fundamentada } \\
\text { sobre uma evidência empirica, mas o abandono } \\
\text { de um programa de pesquisa implica considerações } \\
\text { extra-experimentais. }\end{array}$ \\
\hline 4. A ciência e a objetividade & $\begin{array}{l}\text { A demarcação entre a ciência e a pseudo-ciência } \\
\text { é objetivo no mundo das idéias e proposições. } \\
\text { O compromisso teórico é uma questão do mundo } \\
\text { dos estados mentais, crenças e conseqüências. }\end{array}$ \\
\hline $\begin{array}{l}\text { 5. A ciência e o caráter } \\
\text { absoluto }\end{array}$ & $\begin{array}{l}\text { A ciência não é jamais absoluta. A avaliação deve } \\
\text { compreender uma série de teorias. Não importa qual } \\
\text { parte do corpo da ciência é substituivel, mas sempre } \\
\text { num sentido "progressivo". Ou seja, os substitutos } \\
\text { devem antecipar fatos novos com sucesso. }\end{array}$ \\
\hline 6. A ciência e a verdade & $\begin{array}{l}\text { A verdade absoluta não pode ser atingida } \\
\text { pela ciência. No entanto, programas de pesquisa } \\
\text { cientifica podem, a longo prazo, trazer conseqüências } \\
\text { verdadeiras (menos falsas) e, portanto, aumentar } \\
\text { a "irrefutabilidade". }\end{array}$ \\
\hline $\begin{array}{l}\text { 7. A ciência e a } \\
\text { racionalidade }\end{array}$ & $\begin{array}{l}\text { Se a ciência objetiva a verdade, ela deve objetivar } \\
\text { e manter uma consistência como um importante } \\
\text { princípio regulador. A inconsistência deve ser vista } \\
\text { como um problema que deve ser resolvido. }\end{array}$ \\
\hline 8. A ciência e a falsificação & $\begin{array}{l}\text { Uma teoria é científica somente se ela tem } \\
\text { um conteúdo empirico suficientemente corroborado } \\
\text { sobre a teoria rival. Ou seja, se ela conduz } \\
\text { à descoberta de fatos novos. }\end{array}$ \\
\hline 9. A ciência e a medida & $\begin{array}{l}\text { Enquanto que o experimento permanece ainda } \\
\text { um árbitro imparcial na controvérsia científica } \\
\text { (da medida), a importância de decisões na } \\
\text { metodologia não deveriam ser negligenciadas. }\end{array}$ \\
\hline $\begin{array}{l}\text { 10. A ciência e o teste } \\
\text { empírico }\end{array}$ & $\begin{array}{l}\text { O processo de teste empirico fornece um fundamento } \\
\text { necessário mas jamais suficiente para a refutação. }\end{array}$ \\
\hline
\end{tabular}


Segundo o quadro da página precedente, os itens 1 e 4 mostram que a estrutura da falsificação metodológica sofisticada distingue o mundo das proposições e das idéias do mundo dos estados mentais, das crenças e das conseqüências. O positivismo lógico e o empirismo moderno se relacionam, geralmente, ao primeiro tipo de mundo, enquanto que o relativismo concerne ao segundo nível de abstração.

Com relação à natureza do conhecimento científico (itens 5 e 7), a perspectiva lógica positivista defende que o conhecimento científico não é jamais absoluto. Enquanto a falsificação metodológica sofisticada está de acordo com o empirismo moderno de que o conhecimento científico é principalmente cumulativo (itens $5 \mathrm{e}$ 6), parece bastante claro que a pesquisa científica compreenda um conjunto de decisões metodológicas num contexto particular. Ou seja, aquele de um programa de pesquisa.

\section{Considerações finais}

Lakatos sustenta que várias teorias científicas avançaram, a despeito das refutações aparentes pelos dados empíricos, o que atesta, por esta via, a tenacidade com a qual as teorias são afrontadas por possiveis evidências não-confirmatórias.

Além disso, a perspectiva "lakatosiana" fornece uma descrição das dinâmicas fundamentais do porquê a ciência é progressiva enquanto que é declarado que a avaliação de programas de pesquisa engloba uma série de teorias, e que velhas teorias podem somente ser abandonadas enquanto que outras novas emergem $\mathrm{e}$ antecipam fatos novos com sucesso.

Por fim, a perspectiva "lakatosiana" pode fornecer o veículo da falsificação metodológica sofisticada para o empirismo moderno e preencher a lacuna entre relativistas e empiristas, ao mesmo tempo em que ela reforça os papéis do contexto da pesquisa na forma de um programa de pesquisa, assim como a importância das decisões metodológicas na pesquisa.

\section{Referências bibliográficas}

KUHN, T. S. The logic of scientific discovery. London: Hutchinson, 1970.

LAKATOS, I., MUSGRAVE, A. Criticism and the growth of knowledge. London: Cambridge University Press, 1970.

POPPER, K. R. Objective knowledge: an evolutionary approach. London: Oxford University Press, 1972. - Conjectures and refutations. London: Routledge \& Kegan Paul, 1972. 